\title{
Reflexões sobre o uso das tecnologias móveis digitais no ambiente escolar do IFS
}

\author{
Anne Alilma Silva Souza Ferrete ${ }^{1,}$ Rodrigo Bozi Ferrete ${ }^{2}$ \\ ${ }^{1}$ Departameto de Educação -Programa de Pós-Graduação em Educação (PPGED) - \\ NUCA-Núcleo de Comunicação e Arte (vice-líder) - Universidade Federal de Sergipe \\ (UFS) - São Cristóvão - SE - Brazil \\ ${ }^{2}$ Professor do Instituto Federal de Educação, Ciências e Tecnologia de Sergipe - IFS. \\ Doutorando em Educação - Aracaju - SE - Brazil \\ alilma.ferrete50@gmail.com, rbferretedgmail.com \\ Utilização das tecnologias móveis na educação

\begin{abstract}
This study aimed the relationship the relationship of the Instituto Federal de Ciencias e Tecnologia de Sergipe (IFS) with the concept of cyberculture in their daily lives. The object of study was focused on the testimony of teachers and students regarding the use of mobile technology incorporated into the teaching. For that, we conducted a qualitative research through the IFS analysis of documents and the applicable law; as well as informal conversations with teachers and students, interviews with teachers, on-site observation of teaching practice in all campuses of the IFS. The results showed internal problems generated by the development of both administrative practice and teaching, supported by the exclusion of research and dialogue on the use of mobile digital technology in their teaching and pedagogical practice.
\end{abstract}

Resumo. O presente estudo teve como objetivo compreender a relação do Instituto Federal de Ciências e Tecnologia de Sergipe (IFS) com o conceito de cibercultura em seu cotidiano. O objeto de estudo centrou-se nos depoimentos dos professores e dos alunos com relação ao uso da tecnologia móvel incorporado ao ensino. Para isso, realizamos uma pesquisa de cunho qualitativo através de análise de documentos do IFS e da legislação vigente; além de conversas informais com professores e alunos, entrevistas com professores, observação in loco da prática escolar em todos os campi do IFS. Os resultados apontaram problemas internos gerados pelo desenvolvimento de uma prática tanto administrativa como pedagógica, sustentada pela exclusão de pesquisas e diálogos sobre o uso das tecnologias móveis digitais suas práticas pedagógicas.

\section{Introdução/Justificativa}

Vivemos um período histórico marcado por um ritmo acelerado de mudanças tecnológicas que geram impactos psíquicos, culturais, científicos e educacionais em que conceitos básicos do cotidiano como os de espaço, tempo, real e imaginário vêm sendo 
revistos, reformulados, devido as mudanças estruturais que a sociedade vem passando através de uma evolução cultural. Esses impactos podem ocorrer nas diversas esferas praticamente ao mesmo tempo e com velocidade crescente. Entretanto, isso não vem ocorrendo na esfera educacional do Instituto Federal de Educação, Ciência e Tecnologia de Sergipe (IFS).

O conceito de cultura pode ser compreendido de diversas formas. Levaremos em consideração o pensamento e abordagem de alguns autores, e a partir de então, para chegarmos ao conceito de cibercultura.

Segundo Lemos (2003) podemos pensar o desenvolvimento da cultura a partir de três fases: a fase da indiferença (até a idade média), que se caracteriza pela mistura entre arte, religião, ciência e mito; a fase do conforto (modernidade) em que a natureza é dessacralizada, controlada, explorada e transformada, e a fase da ubiquidade (pós modernidade), caracterizada pela fase da simulação, a fase da cibercultura.

Entretanto, atualmente o conceito de cultura de um determinado grupo social precisa ser estendido a um conceito mais amplo e não pode mais ser delimitado ou caracterizado histórico e geograficamente apenas, tendo em vista que não temos somente um único espaço ou tempo, e sim vários espaços e tempos diversos, frutos do desenvolvimento tecnológico que nos obrigam a pensar a relação da tecnologia e a sociedade não mais separadamente, mas como pilares para a compreensão do conceito atual de cultura, e consequentemente, das culturas existentes.

Trabalhando o conceito de cultura enquanto caracterização dos costumes, regras, crenças e características de determinados grupos sociais, Santaella (2003, p. 35) parte do conceito de que "a cultura representa essencialmente as condições morais do indivíduo, enquanto a civilização significa as convenções da sociedade”. Dessa forma, ela diferencia os conceitos de civilização e cultura, sendo ambos influenciados pela tecnologia que tanto afeta as condições morais do indivíduo, quanto às convenções da sociedade.

Santaella (2003), chama à atenção para o fato de que mudanças nas regras da sociedade estão ocorrendo em ritmo "acelerado frente às mudanças tecnológicas e os consequentes impactos psíquicos, culturais, científicos e educacionais que eles provocam", e que alteram rapidamente conceitos básicos do cotidiano, além de exigir novos modelos de análise adequados a essa nova realidade.

Neste sentido, Lemos (2002) busca compreender como a tecnologia surgiu, e como ela se relaciona historicamente com a sociedade, e, para isso, parte da diferenciação básica entre técnica e tecnologia. Destaca ainda que a tecnologia se constitui nos objetos técnicos, como máquinas e seus respectivos processos de fabricação, enquanto que a técnica está ligada a várias áreas como: dança, economia, esportes, objetos, instrumentos e até máquinas. Faz-se necessária revisão histórica e etnográfica da formação dessa palavra para compreendermos seu significado atual.

Ao analisar a etimologia da palavra técnica, verificamos que tem sua origem do termo grego tekhnè e que pode ser traduzida como arte, modo, estilo. É usada na formação de várias outras palavras como, por exemplo, na palavra matemática, que é formada pelo radial grego matema que significa aprender, conhecer, entender, e o sufixo tica que vem do grego tekhnè, ou seja, pela análise da palavra matemática esta significa a técnica (arte, modo, estilo) de aprender, conhecer e entender.

No intuito de buscar uma compreensão em uma das vertentes sobre o significado de cibercultura, partimos da análise do prefixo "ciber" de cibernética 
associado à palavra "cultura", enquanto conjunto de conhecimentos, técnicas e artefatos, de padrões de comportamento e atitudes que caracteriza uma determinada sociedade. No entanto, Teixeira (2012) afirma que existem diversas interpretações, e em alguns casos até mesmo ambíguos, sobre a etimologia dessa palavra, por isso, explicitamos que a compreendemos, a partir do pensamento de Lèvy (2010, p. 17), que diz que cibercultura trata de um "conjunto de técnicas (materiais e intelectuais), de práticas, de atitudes, de modos de pensamento e de valores que se desenvolvem juntamente com o crescimento do ciberespaço". E continua afirmando que as "técnicas" condicionam as interações sociais, mas não representam a cultura do ciberespaço, que se incorporem no espaço virtual cognitivo das pessoas, na partilha de sentimentos, informações e saberes. E ainda complementa Lèvy (2010, p. 17), "a virtualização é um dos principais vetores da criação da realidade".

Lemos (2002, p. 77) acrescenta a intepretação de Lèvy, e explicita que:

\begin{abstract}
A cibercultura será uma configuração sócio-técnica onde haverá modelos tribais associados às tecnologias digitais, opondo-se ao individualismo da cultura do impresso, moderna e tecnocrática. Com a cibercultura, estamos diante de um processo de aceleração, realizando a abolição do espaço homogêneo e delimitado por fronteiras geopolíticas e do tempo cronológico e linear, dois pilares da modernidade ocidental. No entanto, esta conectividade generalizada não é isenta de críticas.
\end{abstract}

Desta forma, Lemos entende que a cibercultura é a relação entre as tecnologias de comunicação, informação e a cultura, caracterizada por uma nova relação entre tecnologias e sociabilidade, configurando a cultura contemporânea, na qual, todos são estimulados a produzir, distribuir e reciclar conteúdos através de redes sociais que se constituem em uma sociedade conectada, colaborativa, hipertextual, destituída de presencialidade física, e apoiada por interfaces da web.

Portanto, temos uma enorme potencialidade pedagógica em mãos a ser explorada pelos professores nas escolas, e requer que repensemos as práticas atuais, a partir da realidade dos alunos, discutindo suas possibilidades, limitações e problemas existentes, e com a certeza de que não podemos ignorá-la no processo de ensino e de aprendizagem, pois o conceito de cibercultura está em permanente transformação e devemos discutir suas implicações educacionais dentro e fora dos espaços escolares.

Diante dessas considerações, faz-se necessário repensar sobre a abordagem dos conteúdos de ensino, bem como a sua prática contextualizada e integrada ao uso da tecnologia móvel. E poderá possibilitar que os indivíduos realizem seus planos, suas pesquisas em comum acordo, ou seja, entre professores, seus pares e a equipe pedagógica de formação, de acordo com uma situação pré-definida e presente nas relações entre os educadores. Para tanto, segundo Oliveira (2004) é importante aproveitar a volatilidade, a interatividade e a flexibilidade das tecnologias digitais, potencializando práticas multiculturais, inclusivas, pensando no currículo escolar e incorporando as ações e atividades escolares previstas integradas ao uso da tecnologia digital.

Há necessidade de pensar nas diversas possibilidades de proporcionar inclusão digital desses alunos, com a integração das tecnologias móveis no ensino. Vale lembrar que é muito pouca a familiarização da maioria dos educadores com o emprego do computador ou da tecnologia móvel como instrumento educacional, enquanto 
constatamos a boa vontade dos discentes em se fazerem presentes, motivados com a utilização da tecnologia móvel em sala de aula, como fonte de pesquisas na Internet ou até mesmo, em produzirem trabalhos com utilização dos diversos softwares, de acordo com as exigências de suas respectivas áreas. Mediante o que foi descrito anteriormente, vale ressaltar a necessidade de refletir sobre alternativas metodológicas.

\section{Metodologia aplicada}

Definir o método é essencial para o desenvolvimento da pesquisa, a fim de que permita o alcance dos seus objetivos, conforme escolha e aplicação dos modelos mais adequados.

A natureza da pesquisa teve um caráter exploratório, de modo que permitiu uma visão mais precisa da formação e das ações dos professores, tendo em vista as mudanças no cotidiano, no currículo e na cultura escolar, ocorridas diante da utilização da tecnologia móvel. E surgiu a necessidade de novos desafios com relação à formação de professores e gestores, para que o uso da tecnologia se efetivasse como apoio nas atividades pedagógicas, ou seja, a tecnologia realmente integrasse o currículo escolar, com objetivo de promover a cultura digital na instituição.

Por isso, iniciamos esta pesquisa, motivados pelo seguinte problema de pesquisa: Como a Instituição de Ensino Tecnológica de Sergipe trabalha o conceito de cibercultura em seu cotidiano?

Para tentarmos responder a essa pergunta, lançamos mão do seguinte objetivo de pesquisa: compreender a relação do IFS com o conceito de cibercultura em sua cultura escolar. Para alcança-lo, investigamos tanto a parte administrativa quanto a parte pedagógica e os alunos da Instituição frente às mudanças tecnológicas vivenciadas pela sociedade e pela comunidade na qual a Instituição está inserida.

Para chegarmos às respostas das questões investigadas, enquanto fundamentação metodológica, realizamos uma pesquisa de cunho qualitativo, voltada para o processo e não, simplesmente, para o resultado e produto. Através da análise qualitativa coletamos e analisamos a maior parte das informações obtidas com aplicação da entrevista, tais como: o que os professores entendem por cibercultura? Como desenvolvem suas aulas? Quais tecnologias móveis utilizam em sala de aula? Quais mudanças metodológicas realizadas nos últimos anos, frente aos avanços tecnológicos que permeiam a sociedade. Quanto aos alunos, aplicamos questionários e procuramos questionar: o que acham da metodologia empregada pelos professores? O que entendem por cibercultura? Quais recursos tecnológicos que possuem à disposição durante as aulas? Quais recursos tecnológicos disponíveis no IFS para eles? E quais tecnologias móveis mais utilizam em sala de aula? Entre outras questões.

Com a revisão bibliográfica sobre a temática, procuramos fundamentação teórica de alguns autores. Além de procurarmos reunir alguns documentos do IFS para análise, como a legislação; além disso, fizemos análise dos dados coletados através de entrevistas, conversas informais com professores e os questionários aplicados aos alunos, buscando entender como ocorrem oficialmente e na prática, a gestão da escola e as aulas, os recursos tecnológicos utilizados; enfim, o que o IFS está fazendo para acompanhar o desenvolvimento tecnológico. Além disso, utilizamos observação in loco, da prática escolar em todos os campi do IFS para confrontarmos as falas dos sujeitos com as ações praticadas. 
Devido ao tamanho da população da pesquisa, mais de 10000 alunos, 500 professores, seis campi (Aracaju, São Cristóvão, Lagarto, Estância, Itabaiana, Nossa Senhora da Glória e a Reitoria), optamos por constituir uma amostra intencional e não probabilística, constituída por três professores que encontramos ministrando aulas nos laboratórios de cada campus, no momento de nossas visitas, e os alunos que assistiam a essas aulas. Além disso, entrevistamos mais cinco professores que possuem cargos administrativos, sendo um de cada Pró-Reitoria (Adminstração; Gestão de Pessoas; Pesquisa e Extensão; Desenvolvimento Institucional e Ensino).

Após a coleta, organização e análise dos dados, estruturamos o presente artigo apresentando inicialmente a metodologia da pesquisa seguida do que compreendemos por cibercultura, pois são conceitos que possuem muitas interpretações e significados, e sentimos necessidade de esclarecer nossa compreensão sobre esses conceitos. Para, só então, podermos analisar o conceito de cibercultura nessa cultura escolar, a fim de buscarmos compreender melhor a interface da cibercultura ou cultura das mídias com a educação, que acreditamos contribuir para o entendimento dos desafios apresentados na cultura atual do IFS.

\section{Experiências vivenciadas}

Após breve discussão apresentada de cultura e cibercultura, somos levados explicitar nossa compreensão sobre a relação da cibercultura na cultura escolar do IFS. Para isso, consideramos a cultura escolar como: práticas, modos, hábitos, comportamentos e normas sociais praticados dentro da escola, inclusive durante o processo de ensino e de aprendizagem.

O IFS tem, desde a sua implantação em 1909, vivenciado diversas modificações estruturais, tanto administrativas, quanto pedagógicas, iniciando sua história como Escola de Aprendizes, até chegar à modalidade de Educação à Distância - EaD, em 2012. Nesse processo o IFS recebeu várias nomenclaturas, entre as quais destacamos a de 1965, quando, a então Escola Industrial de Aracaju, passou a ser denominada de Escola Técnica Federal de Sergipe, ofertando ensino médio e formação profissional, concomitantemente.

Em 2008, com a proposta de integração das autarquias federais através da Lei n. ${ }^{\circ} 11.892$ e Portaria n. ${ }^{\circ} 116 /$ SETEC, de 31 de março de 2008, com a unificação do Centro Federal de Educação Tecnológica de Sergipe (CFET/SE) e Escola Agrotécnica Federal de São Cristóvão (EAFSC), deu-se origem ao Instituto Federal de Sergipe Ciência e Tecnologia-IFS, composto por três Campi: Aracaju, São Cristóvão e Lagarto, sediados nos municípios de seus respectivos nomes. A partir de 2009, com a segunda fase de expansão o IFS, fundamentado na análise de variáveis geográficas, socioambientais, econômicas e culturais, e contemplando de acordo com os arranjos produtivos locais (APL) de agricultura, comércio e indústria, implantou mais três campi: Estância, Nossa Senhora da Glória e Itabaiana, totalizando atualmente, seis campi e uma Reitoria localizada na cidade de Aracaju. (PDI/IFS/2009).

Assim, o IFS contempla, entre outras finalidades:

[...] ofertar educação profissional e tecnológica, em todos os seus níveis e modalidades, formando e qualificando cidadãos com vistas na atuação 
V Congresso Brasileiro de Informática na Educação (CBIE 2016)

Anais dos Workshops do V Congresso Brasileiro de Informática na Educação (CBIE 2016)

profissional nos diversos setores da economia, com ênfase no desenvolvimento socioeconômico local, regional e nacional. (PDI/IFS, 2009).

Diante do exposto, os Institutos Federais se transformaram em instituições de educação superior, básica e profissional, pluricurriculares e multicampi, especializados na oferta de educação profissional e tecnológica, nas diferentes modalidades de ensino. Destacando, ainda que, para efeito de regulação, avaliação e supervisão das instituições e dos cursos de educação superior, os Institutos Federais são equiparados às universidades federais, ou seja, os Institutos surgem com a função também de ofertar o ensino superior, tendo a flexibilidade de atuar em várias modalidades e níveis de ensino.

Ele apresenta como características específicas: desenvolvimento de pesquisa aplicada em detrimento da pesquisa pura; possui normas específicas para oferta de vagas de seus cursos. Além dessas mudanças, destacamos que, a partir do processo de criação do IFS, ocorreram:

1.Fusão entre duas instituições de ensino, o CEFETSE e a EAFSC; lembrando que o CEFET tinha em sua composição a unidade descentralizada de Lagarto (UNED), e trabalhava com cursos voltados para a área industrial; enquanto a EAFSC trabalhava com cursos voltados para a área agrícola, tendo, inclusive o regime de internato para seus alunos;

2.Criação de mais três campi: Estância, Itabaiana e Nossa Senhora da Glória, o que proporcionou um grande aumento de servidores, alunos e uma nova realidade multicampi;

3.Autorização da construção de mais quatro novos campi, com sede nos municípios de Poço Redondo, Propriá, Tobias Barreto e Nossa Senhora do Socorro;

Assim, o IFS possui hoje uma Reitoria, onde fica a parte administrativa sistêmica, responsável pela gestão orçamentária, administrativa e pedagógica de seus campi que ofertam 53 cursos nas modalidades de cursos Técnico, Subsequente, Educação de Jovens e Adultos, Superior, Pós-Graduação e Educação a Distância (EaD).

Atualmente o IFS apresenta características novas a partir de sua criação. Não possui ainda, uma identidade consolidada, ou seja, uma cultura escolar definida. $\mathrm{Na}$ verdade, sua cultura escolar encontra-se em fase de identificação, pois entendemos que todas as culturas escolares estão em construção devido a cultura não ser um produto final, acabado, e sim, algo em constante construção. Desta forma, compreendemos que, ao analisarmos a cibercultura na cultura escolar do IFS, através desta pesquisa, estaremos colaborando com a identificação e construção da cultura escolar e administrativa do IFS.

Vale destacar que a informatização das escolas é um dos grandes desafios do século XXI, pois o mundo está cada vez mais dependente das tecnologias, uma vez que nos permitem utilizar as ferramentas disponíveis e acessar as mais variadas conexões com todas as partes do mundo, em diferentes países, com as mais diversificadas culturas, extrapolando e ampliando todos os limites de tempo e de espaço territoriais e conexões globais. No entanto, esse processo tem ocorrido de forma acelerada e as escolas, de um modo geral, não têm conseguido acompanhá-lo, conforme observamos no IFS.

Apesar de ser intitulado Instituto Federal de Educação, Ciência e Tecnologia de Sergipe, observamos que ele se constitui nos mesmos elementos pedagógicos característicos de um ensino tradicionalista, fundamentado no conhecimento do 
professor, como o ser que detém todo o conhecimento. Apesar da maioria dos Campi possuírem conexão wifi, os professores normalmente não utilizam as tecnologias móveis, e quando fazem, em sala de aula, geralmente é para preencher o diário de classe, disponibilizado online.

No entanto, observando várias salas de aula através das janelas ou portas, sem interferir nas mesmas ou chamar à atenção dos alunos ou professores, constatamos que os alunos estão constantemente conectados à internet através de seus dispositivos smartphones, durante boa parte das aulas. Em conversas informais com esses alunos, durante o intervalo das aulas, estes revelaram que a maior parte do tempo ficam conectados em chats de bate papo com outros alunos ou com outros amigos, e raramente utilizam essa ferramenta para pesquisar algo relacionado ao conteúdo estudado, pois entendem que o professor possui todo o conhecimento necessário do assunto e não possuem estímulo ou orientação do docente para pesquisar, pois consideram, na maioria das vezes, o assunto "chato", e desinteressante.

Por essas observações constatamos que a abstenção de professores e gestores educacionais na utilização das tecnologias digitais na educação, envolve uma questão sociocultural mais ampla e profunda, e sugerimos adaptar-se à época em que vivemos, marcada por novos modos de comunicação, estilo de vida, identidades, entretenimento, interatividade, que geram a necessidade de novas formas de ensinar e aprender, além de poder manter o aluno interessado e motivado em sala de aula.

A adaptação a esse novo cenário que envolve o uso das tecnologias móveis de forma geral, requer uma estratégia definida, com base em uma clara compreensão da nova cultura emergente, dos valores explícitos, dos objetivos educacionais, e que evitem o instrucionismo mecanizado. Esse fato é reforçado quando observamos alunos de todos os campi do IFS utilizando as dispositivos móveis durante as aulas em diversas atividades como: chats, facebook, instagram, whatsapp; além de jogos online e offline; download de músicas ou simplesmente na internet para passar o tempo, enquanto os professores ficam a frente, na sala de aula realizando seus discursos educacionais, muitas vezes vazios de significados para boa parte dos alunos.

Essas são atitudes observadas constantemente no IFS, e através da amostragem realizada na pesquisa em cada um desses Campi, constatamos que, em média, a cada 10 alunos, 9 possuem smartphone, e 6 fazem uso dessa tecnologia móvel diariamente durante as aulas. Levando em consideração que as turmas do IFS possuem, em média, 40 alunos, temos uma média geral em cada sala de aula, de 36 alunos com essa tecnologia, ou em termos percentuais, 90\% dos alunos. Sendo que 24 utilizam as tecnologias digitais durante as aulas, ou em termos estatísticos, 60\% dos alunos a utilizam independente da autorização do professor.

Esses dados chamam bastante a atenção principalmente, por dois motivos: a capacidade financeira dos alunos em adquirir tecnologias móveis modernas; e a possibilidade pedagógica que esse cenário possibilita aos professores que, simplesmente a ignoram ou registem, e tentam impedir que os alunos a utilizem durante suas aulas.

Como o IFS possui, em cada Campus, diversos laboratórios para atender aos seus cursos, realizamos pesquisa após algumas aulas nesses laboratórios para sabermos o que foi trabalhado nessas aulas e o que os alunos acharam da integração das tecnologias móveis digitais. Após coletas dos dados, verificamos que aproximadamente $90 \%$ dos discentes alegaram preferir as aulas ministradas nos laboratórios às ministradas nas salas de aula, por considerá-las mais interessantes e divertidas. No entanto, mesmo 
nessas aulas, os alunos continuaram utilizando os recursos tecnológicos de seus dispositivos móveis, mesmo nos laboratórios que possuem computadores com acesso a internet, pelo simples motivo de restrição à navegação na internet presente nos laboratórios ou receio do professor, ou até dos outros colegas, observarem o que estão fazendo.

De acordo com a pesquisa realizada, em relação às aulas práticas nos laboratórios, podemos evidenciar dois fatos principais: não importa quanto à aula seja interessante ou não para os alunos, estes sentem uma necessidade de continuarem conectados, utilizando seus dispositivos móveis; e a importância da privacidade do que fazem, enquanto estão conectados, apesar da exposição de suas ações em canais de comunicação como o facebook, instagram, whatsapp, ou seja, aceitam se expor a todos que também estão conectados a esses canais.

De outra forma, apesar de os professores praticamente não fazerem uso dessas tecnologias em sala de aula, muitos docentes têm utilizado para comunicar-se com os discentes, pois conseguem, através desses canais de comunicação, aproximar-se e conhecer melhor seus alunos do que através de conversar presenciais durante as aulas ou nos intervalos entre uma aula e outra. Esse fato pode ser explicado pelo fato dos alunos se sentirem mais à vontade para se expressar no mundo virtual, do que no presencial, ou ainda, em alguns casos verificados, por não visualizarem, no mundo virtual, toda a autoridade do professor, uma vez que, no mundo virtual, todos são usuários, não existindo hierarquias.

Corroborando com o contexto exposto anteriormente, o mundo virtual oferece várias possibilidades de comunicação e interação que tem atraído, cada vez mais, a atenção, principalmente, da juventude, oferecendo uma nova maneira de ser e estar no mundo e até mesmo, um novo mundo denominado de ciberespaço, por inúmeros autores. Estudos e pesquisas sobre essas relações ainda são poucos e difíceis de serem realizados, pois, as novidades são muitas e se modificam velozmente.

Esses dois vetores de quantidade e velocidade são grandes desafios para a sociedade como um todo e, principalmente, para os professores que, em suas formações são, muitas vezes, doutrinados por currículos ultrapassados, resistentes ao tempo, uma vez que na maior parte, os professores que elaboraram esses currículos não vivenciaram e preferiram ignorar as mudanças que vem ocorrendo. Isso gera um ciclo vicioso que não pode ser utilizado como justificativa para a não abertura das salas de aula ao ciberespaço, pois entendemos que, ser professor é estar em constante estado de aprendizagem, permitindo aos professores se arriscarem e começarem a experimentar novas possibilidades pedagógicas dentro da nova realidade vivenciada pelos discentes.

As mudanças de paradigmas em qualquer situação requer cautela, persistência e, às vezes, confrontos. Assim no IFS, observamos normas sistêmicas que dificultam a implementação de novas práticas pedagógicas em cada campus, por apresentar especificidades, pois possuem identidades próprias. Observamos no IFS uma situação geral que dificulta a implementação de novas práticas pedagógicas, devido a burocratização das normas de ensino. Esse fato é constatado em todos os seis campi, por serem subordinados a uma Reitoria, externa a todos os campi, que tem como objetivo, criar e fiscalizar o cumprimento de todas as diretrizes de ensino, pesquisa e extensão. Desta forma, qualquer curso dentro do IFS, para reformular seu projeto pedagógico, precisa justificar à Reitoria, a necessidade e importância de tal ação, e esta é quem formará uma comissão de trabalho, instituída através de portaria, com 
membros e prazo para conclusão do trabalho, e que, após isso, será avaliado e aprovado ou não pelos órgãos superiores competentes da Reitoria.

O processo burocrático se torna ainda mais injusto quando observamos que, cada campus possui uma identidade específica. Por exemplo, temos dois campi agrícolas e quatro industriais, sendo que um possui regime de internato para parte de seus alunos. Queremos mostrar com isso, que cada campus possui uma identidade própria, regida por regras gerais que, muitas vezes, não atendem às suas necessidades. Essa situação, tornase ainda mais complexa, quando observamos a falta de diálogo entre cursos ofertados no Instituto dentro do mesmo campus, com os cursos dos outros campi. Não identificamos qualquer comunicação entre as coordenações dos cursos de campi diferentes, além de comunicação precária entre os coordenadores de cursos do mesmo campus.

Observamos problemas de comunicação também entre os professores, tanto em uma visão macro, pois não possuem, de modo geral, comunicação com os professores de outros campi, como também do próprio campus, e em alguns casos, do próprio curso. Identificamos em alguns campi a preocupação com o diálogo entre os professores do mesmo curso, sendo realizadas periodicamente reuniões entre os mesmos, mas em outros campi, isso não é realizado, o que proporciona o fato de os professores não conhecerem e nem saberem quem são os professores que ministram aulas das outras disciplinas de um determinado curso.

Constatamos que, apesar do IFS em sua nomenclatura oficial, ser um Instituto Tecnológico, este vem apresentando nas esferas administrativa e pedagógica, inúmeros problemas que poderiam ser solucionados ou amenizados, através dos recursos tecnológicos disponíveis para ajudar na comunicação da Reitoria com os campi, entre os coordenadores e professores dos cursos, entre os professores e alunos, Reitoria e professores, Reitoria e alunos, coordenadores e alunos, enfim, entre todos que participam do IFS.

\section{Considerações finais}

Acreditamos que, com a incorporação administrativa de práticas de comunicação mais eficazes e atuais, estas serão refletidas nos processos pedagógicos e também nas aulas dos professores, estimulando estes a refletir, inclusive sobre sua prática pedagógica frente às novas possibilidades metodológicas disponíveis aos alunos. Apesar de termos identificado que, no processo de ensino e de aprendizagem, não basta apenas fazer uso das tecnologias móveis para conseguir total atenção e interesse dos alunos, pois existem outras situações e problemas que não podem ser resolvidos simplesmente pelo uso das tecnologias. Entendemos que estas observações podem contribuir significativamente para a melhoria do processo de ensino e de aprendizagem, no que se refere à comunicação e às relações entre o professor e seus alunos, além da gestão escolar.

A melhoria na comunicação pode contribuir com troca de experiências, tanto pedagógicas quanto administrativas, ajudando tanto a gestão escolar, quanto nas práticas de ensino, tendo em vista que, as mudanças tecnológicas na sociedade têm ocorrido de forma acelerada e não existem respostas, em alguns casos, nesse momento, frente aos novos conceitos como o de cibercultura, ciberespaço, entre outros em relação ao que é correto ou não. O que não se pode e não se deve ser feito é ignorar essas transformações, esses novos conceitos e tudo o que eles trazem de positivo e negativo, e sim, arriscar-se na tentativa de entendê-los, utilizando as ferramentas e técnicas que eles trazem, ou seja, deve-se arriscar a entrar nesse mundo novo do qual os alunos já fazem parte. 
V Congresso Brasileiro de Informática na Educação (CBIE 2016)

Anais dos Workshops do V Congresso Brasileiro de Informática na Educação (CBIE 2016)

Desta forma, os resultados apontam problemas internos, gerados pelo desenvolvimento de uma prática, tanto administrativa como pedagógica sustentada pela exclusão de pesquisas e diálogos sobre o uso das tecnologias móveis digitais incorporadas ao processo de ensino e de aprendizagem em sala de aula.

\section{References}

IFS. Relatório de Gestão IFS 2012. Sergipe: IFS, 2012. Disponível em: www.ifs.edu.br/images/reitoria/2012/rgi.pdf Acesso em: 22 ago. 21013.

IFS. PDI: Plano de Desenvolvimento Institucional. Sergipe: IFS, 2009. Disponível em: <www.ifs.edu.br/images/reitoria/2011/pdi.pdf>. Acesso em: 22 ago. 2013.

LEMOS, A. Cibercultura, tecnologia e vida social na cultura contemporânea. Porto Alegre: Sulina, 2002.

LEMOS, A. Cibercultura: alguns pontos para compreender a nossa época. In: LEMOS, A.; CUNHA, P. Olhares sobre a cibercultura. Porto Alegre: Sulina, 2003.

LÈVY, P. Cibercultura. São Paulo: Edi-tora 34, 2009.

O que é virtual? São Paulo: Editora 34, 2010

NÓVOA, Antônio (org.). As Organizações Escolares em Análise. Lisboa: Portugal: Edições Dom Quixote, 1999.

Oliveira, J. M. A. (2004) "O hipertexto como imaginação do currículo e de conhecimentos produzidos na escola", Ano 2 - Voll.

SANTAELLA, Lucia. Culturas e artes do pós-humano: da cultura das mídias à cibercultura. São Paulo: Paulus, 2003.

TEIXEIRA, M. Cyberculture: from Plato to the virtual universe. The architecture of collective intelligence. Munique: Grin Verlag, 2012a.

* Doutorado em Educação. Vice líder do Grupo de Pesquisa NUCA, professora Pesquisadora do Grupo de Pesquisa do NUPIEPED, e do EDaPECI. É professora do Departamento de Educação e do Programa de Pós-Graduação em Educação da Universidade Federal de Sergipe. E-mail: alilma.ferrete50@gmail.com.

** Aluno do curso de Doutorado em Educação da UFS, Professor do Instituto Federal de Sergipe (IFS), rbferrete @ gmail.com. 